\title{
The prevalence of strabismus types in strabismic Iranian patients
}

\author{
Masoud Khorrami-Nejad' \\ Mohamad Reza Akbari ${ }^{2}$ \\ Bahram Khosravi' \\ 'Department of Optometry, Faculty \\ of Rehabilitation, Shahid Beheshti \\ University of Medical Sciences, Tehran, \\ Iran; ${ }^{2}$ Eye Research Center, Farabi Eye \\ Hospital, Tehran University of Medical \\ Sciences, Tehran, Iran
}

Correspondence: Mohammad Reza Akbari

Eye Research Center, Farabi Eye Hospital, Tehran University of Medical Sciences, Qazvin Square, Tehran |3366|635I, Iran

Tel +98 2I 55400003 , ext 14

Emailmrakbari83@hotmail.com
This article was published in the following Dove Press journal: Clinical Optometry

Purpose: To determine the frequency of different types of strabismus and amblyopia in the patients of strabismus clinics from 2008 to 2014.

Methods: This retrospective cross-sectional study was conducted using data from the archives of Farabi Hospital in Tehran, Iran, from 2008 to 2014. The study consisted of using records of strabismic patients. From these, strabismus types and associated abnormalities, types of amblyopia and other ocular pathological findings were recorded.

Results: In this study, 1174 strabismic patients were studied. Accommodative esotropia (ET) was the most prevalent type of strabismus accounting for $25.04 \%$ of all strabismic patients while intermittent exotropia (XT), nonaccommodative ET and partially accommodative ET, with $12.09 \%, 11.24 \%$ and $10.39 \%$, respectively, were relatively common. Also, $63.03 \%$ of all strabismic patients had esodeviation with XT coming second accounting for $24.53 \%$ of patients. Other ocular pathologic findings in addition to strabismus were found in 236 (20.1\%) patients. The most common association with those types of strabismus was inferior oblique over action accounting for $11.07 \%$ of all cases, and 88 patients had nystagmus in addition to strabismus. Significantly $45 \%$ of patients had no amblyopia and $37 \%$ of patients had a combined type of amblyopia which was the most common type of amblyopia found in strabismic patients.

Conclusion: The prevalence of ET was two and a half times more than XT and almost half of strabismic patients suffer from amblyopia. This study suggests that strabismus screening of children could be useful in the early detection of strabismus, appropriate management of it and prevention of strabismic amblyopia.

Keywords: horizontal deviation, amblyopia, vertical deviation, inferior oblique over action

\section{Introduction}

Strabismus is a very common ocular problem found at clinics of optometry and ophthalmology. In the USA, 3-5\% of children are affected with 126,400 new cases occurring each year. The national prevalence of squint is $5.4 \%$ and this suggests that there are 7.02 million patients with strabismus in a population of 130 million. ${ }^{1}$ Strabismus constitutes a medical, social and psychological problem. Many studies investigating the prevalence of strabismus and its types have been conducted.

The prevalence of convergent squint varies in different parts of the world; however, esotropia (ET) is the most common form of strabismus constituting from a half to two thirds of all misaligned eyes. ${ }^{2}$ In the US, ET was prevalent amongst $75 \%$ of total cases. ${ }^{3,4}$ In Ibadan, Nigeria, ET was found in $80 \%$ of total cases. ${ }^{5}$ Similarly in Ireland (UK), ET was found to be five times more common than exotropia (XT). ${ }^{6}$ 
However, the prevalence of strabismus differs between various races and the prevalence of different types of strabismus also varies according to race. An example of this is a study on preschool children in Ethiopia, where ET was found to be most the common type of strabismus. ${ }^{7}$ However, in Japanese children, XT was the most prevalent type of squint. ${ }^{8}$ According to the Baltimore Pediatric Eye Disease Study, manifest strabismus was found in 3.3\% of white and $2.1 \%$ of African American children and ET and XT each accounted for close to half of all strabismus in both groups. ${ }^{9}$

Population-based data concerning the prevalence of strabismus or the relative prevalence of its types is not readily available for Iranians. This study presents the relative prevalence of various types of squint and also other pathologic findings that might be associated with it.

\section{Methods}

The study sample consisted of 1174 patients that were referred to the strabismus clinic at Farabi Hospital in Tehran, Iran, between the years 2008 and 2014. This study was in accordance with the tenets of the Declaration of Helsinki and the ethics committee of our strabismus clinic in Farabi Eye Hospital and Tehran University of Medical Science approved the study. The records were de-identified and anonymous.

This study was conducted using the medical records of patients that had one of the types of strabismus. It should be noted those patients who showed an ortho response to the cover test with no head posture were excluded from this study. All patients were examined by two well-educated and experienced examiners. All patients underwent ocular examinations such as cover test, Krimsky test, measuring corrected distance visual acuity (CDVA), manifest refraction, and slit lamp and fundus evaluations.

Strabismus was defined as 1 prism diopter or more misalignment of the visual axes of the eyes measured by unilateral cover test. Accommodative ET was defined as $>2.00 \mathrm{D}$ of hyperopia, uncorrected ET of $>10^{\Delta}$ for distance or near, and corrected ET of $\leq 10^{\Delta}$ for distance and near sight with use of full cycloplegic hyperopic correction. Early onset ET was defined as an initial manifest esodeviation, documented by an ophthalmologist, with onset between birth and 6 months of age. Nystagmus was defined as an ocular oscillation characterized by an anomalous slow movement followed by either a corrective fast movement (jerk nystagmus) or a second slow movement (pendular nystagmus). The recorded data included: age, gender, type and amount of refractive error, CDVA of each eye, the type and amount of deviation, asso- ciated condition with strabismus and anterior and posterior segment eye abnormalities.

\section{Examination}

In our clinic, visual acuity testing with the Snellen Eye Chart was done at $6 \mathrm{~m}$ distance if oral communication with the patient was practical. Binocular vision assessment was made using the cover test, and ocular motility was assessed in nine positions of gaze, testing both ductions and versions. Refractive errors and keratometry was measured with the Topcon auto-kerato refractometer KR 8800 and the Heine Beta200 retinoscope.

Amblyopia is a unilateral or bilateral reduction of CDVA that occurs in the setting of an otherwise normal eye, or a structural abnormality involving the eye or visual pathway, with reduction in visual acuity that cannot be attributed only to the effect of the structural abnormality. Amblyopia was defined as a difference of visual acuity of two lines or more between the eyes and a CDVA of 20/30 or worse resulting from anisometropia and strabismus or both. ${ }^{10}$

In addition to them, the result of direct ophthalmoscopy and biomicroscopy was taken into account, to exclude organic amblyopia from functional amblyopia. Statistical analysis was performed using SPSS software for Windows (Version 22; IBM Inc, Armonk, New York, USA). Prevalence was calculated as the ratio of the number of individuals with any type of strabismus to the total number evaluated.

\section{Results}

In this study, the medical records of 1174 patients were studied. The age of the patients ranged from 0 to 18 years old. Data from 617 male and 557 female patients were used.

A total of $1048(89.27 \%)$ strabismic patients had horizontal, and 126 (10.73\%) had vertical, deviation. Isolated vertical strabismus type was found in 42 patients, whereas 84 patients had combined vertical and horizontal deviations.

Figure 1 shows that ET was the most common type of strabismus between strabismic patients; XT came second followed by vertical deviation. It was found that ET was two and a half times more prevalent than XT and about six times more prevalent than vertical deviation.

It should be noted that in this study $94.9 \%$ of the deviations started in the first decade of the patient's life.

Tables 1 and 2 show that accommodative ET was the most prevalent type of strabismus accounting for $25.04 \%$ of all strabismic patients and intermittent XT, nonaccommodative ET and partially accommodative ET were also relatively 


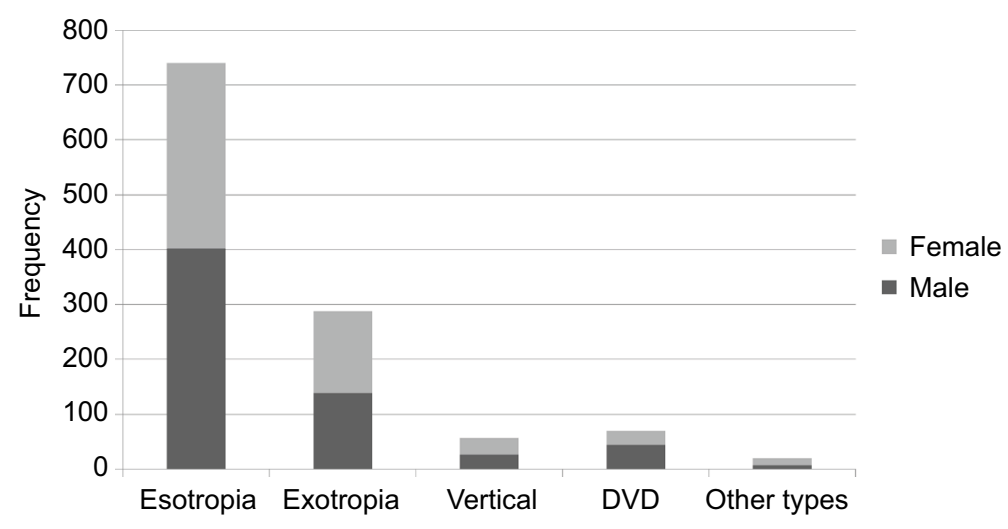

Figure I The relative prevalence of various types of strabismus to the total number of strabismic patients. Abbreviation: DVD, dissociated vertical deviation.

Table I Prevalence of various types of esotropia related to the total number of strabismic patients

\begin{tabular}{|c|c|c|c|c|c|c|c|}
\hline \multirow[t]{3}{*}{ Types of esotropia } & \multicolumn{4}{|c|}{ Gender } & \multicolumn{3}{|c|}{ Total } \\
\hline & \multicolumn{2}{|c|}{ Female } & \multicolumn{2}{|c|}{ Male } & \multicolumn{2}{|c|}{$\begin{array}{l}\text { In esotropic } \\
\text { patients }\end{array}$} & \multirow{2}{*}{$\begin{array}{l}\text { In strabismic } \\
\text { patients } \\
\%\end{array}$} \\
\hline & $\mathbf{N}$ & $\%$ & $\mathbf{N}$ & $\%$ & $\mathbf{N}$ & $\%$ & \\
\hline Accommodative esotropia & 154 & 52.4 & 140 & 47.6 & 294 & 39.72 & 25.04 \\
\hline Nonaccommodative esotropia & 71 & 53.8 & 61 & 46.2 & 132 & 17.83 & 11.24 \\
\hline Partially accommodative esotropia & 63 & 51.7 & 59 & 48.3 & 122 & 16.48 & 10.39 \\
\hline Early onset esotropia & 28 & 38.9 & 44 & 61.1 & 72 & 9.7 & 6.13 \\
\hline DRS type I & 26 & 61.9 & 16 & 38. 1 & 42 & 5.7 & 3.57 \\
\hline Micro esotropia & 6 & 27.3 & 16 & 72.7 & 22 & 3 & 1.83 \\
\hline Sensory esotropia & 2 & 25 & 6 & 75 & 8 & I.I & 0.68 \\
\hline Other type & 16 & 33.3 & 32 & 66.7 & 48 & 6.5 & 4.08 \\
\hline Total & 366 & & 374 & & 740 & 100 & 63.03 \\
\hline
\end{tabular}

Abbreviation: DRS, Duane's retraction syndrome.

Table 2 Prevalence of various types of exotropia related to the total

\begin{tabular}{|c|c|c|c|c|c|c|c|}
\hline \multirow[t]{3}{*}{ Types of exotropia } & \multicolumn{4}{|c|}{ Gender } & \multicolumn{3}{|c|}{ Total } \\
\hline & \multicolumn{2}{|c|}{ Female } & \multicolumn{2}{|c|}{ Male } & \multicolumn{2}{|c|}{$\begin{array}{l}\text { In exotropic } \\
\text { patients }\end{array}$} & \multirow{2}{*}{$\begin{array}{l}\text { In strabismic } \\
\text { patients } \\
\%\end{array}$} \\
\hline & $\mathbf{N}$ & $\%$ & $\mathbf{N}$ & $\%$ & $\mathbf{N}$ & $\%$ & \\
\hline Intermittent XT & 72 & 50.7 & 70 & 49.3 & 142 & 49.3 & 12.09 \\
\hline Constant XT & 66 & 55.9 & 52 & 44.1 & 118 & 41.8 & 10.05 \\
\hline DRS type 2 & 5 & 62.5 & 3 & 27.5 & 8 & 2.8 & 0.68 \\
\hline Other type & 7 & 35 & 13 & 65 & 20 & 6.9 & $\mathrm{I} .70$ \\
\hline Total & 150 & 52.08 & 138 & 47.92 & 288 & 100 & 24.53 \\
\hline
\end{tabular}

Abbreviations: XT, exotropia; DRS, Duane's retraction syndrome.

common, accounting for $12.09 \%, 11.24 \%$ and $10.39 \%$ of patients, respectively.

As can be seen in Table 3, the most common type of vertical deviation was dissociated vertical deviation (DVD) which accounted for more than half of patients with vertical deviation. Cyclovertical deviation was the least prevalent type of vertical deviation and was found in only four patients. Complete third
Table 3 Frequency distribution of patients with vertical deviation

\begin{tabular}{|c|c|c|c|c|}
\hline \multirow[t]{3}{*}{ Vertical deviation types } & \multicolumn{4}{|c|}{ Gender } \\
\hline & \multicolumn{2}{|c|}{ Female } & \multicolumn{2}{|c|}{ Male } \\
\hline & $\mathbf{N}$ & $\%$ & $\mathbf{N}$ & $\%$ \\
\hline Dissociated vertical deviation & 26 & 37.1 & 44 & 62.9 \\
\hline Hypertropia & 22 & 52.4 & 20 & 47.6 \\
\hline Hypotropia & 8 & 57.1 & 6 & 42.9 \\
\hline Total & 56 & 44.4 & 70 & 55.5 \\
\hline
\end{tabular}


nerve palsy also was the least prevalent kind of paralytic form of strabismus and was found in only three patients.

As shown in Figure 2 and Table 4, 79.90\% of strabismic patients had no other ocular abnormalities. However, 130 patients (11.07\%) had inferior oblique over action (IOOA) which was the most common type of associated condition with strabismus. Also, 88 (7.49\%) patients had nystagmus.

The study found that the majority of strabismic patients $(45 \%)$ did not have amblyopia. The combined type (Aniso-strabismic amblyopia) was the most common type of amblyopia accounting for 134 patients (37\%) and the least frequent in the study was strabismic amblyopia, found in 102 patients $(16 \%)$.

\section{Discussion}

In the present study, ET, which was discovered in $63.03 \%$ of patients, was found to be the most common type of strabismus between strabismic patients. EX was found in $24.53 \%$ of patients. EX and ET are also common strabismus types and similar results were seen in studies by Matsuo and Matsuo ${ }^{11}$ on 86,220 Japanese preschool children, and Yu et al ${ }^{12}$ in Hong Kong on 2704 strabismus patients. However, in other studies of Asian people and in Brazil, XT was the most common type of strabismus. ${ }^{13-15}$ One of the reasons for the difference in results amongst our study and other studies was the role of race in the prevalence of strabismus types. ${ }^{16} \mathrm{EX}$ has been reported to be more prevalent among Asian and African American populations than among Caucasians. ${ }^{17}$

The results demonstrated that ET was two and a half times more prevalent than XT and about six times more prevalent than vertical deviation. Several studies of clinical populations have reported that ET occurs approximately 3-5 times as often as XT in children. ${ }^{6,18}$ However, in America, the National Health Survey of individuals aged between 4 and 74 years found a higher prevalence of XT $(2.1 \%)$ than ET $(1.2 \%)$ in the US population. This difference is probably related to the fact that the overall prevalence of strabismus in persons 55-75 years of age (in whom XT is more common) is $6.1 \%$ substantially greater than for very young children $1-3$ years of age (1.9\%) or children and adults $4-54$ years of age $(3.3 \%) .{ }^{19}$ Rajavi et $\mathrm{al}^{20}$ found that the prevalence rate of XT (1.3\%) was more than ET (1\%) among primary school children but they studied a normal population whereas this study was performed on strabismic patients. On the other hand, in our study the prevalence of XT may be underestimated because it is most often an intermittent strabismus, and most of our patients were young children when ET is more common at this age.

In the present study, $56.2 \%$ of all isotropic patients were fully or partially accommodative. Other researchers also

Table 4 The prevalence of cranial nerve palsy and some signs associated with various types of strabismus

\begin{tabular}{lll}
\hline & \multicolumn{2}{l}{ In strabismic patients } \\
\cline { 2 - 3 } & $\mathbf{N}$ & $\%$ \\
\hline IOOA & 130 & 11.07 \\
DVD & 51 & 4.34 \\
V pattern & 39 & 3.32 \\
Ptosis & 28 & 2.38 \\
4 nerve palsy & 21 & 1.79 \\
A pattern & 18 & 1.53 \\
6 nerve palsy & 14 & 1.92 \\
Epicanthal fold & 12 & 1.02 \\
Cross fixation & 11 & 0.93 \\
SOOA & 8 & 0.68 \\
3 nerve palsy & 3 & 0.26 \\
Total & 335 & 28.53 \\
\hline
\end{tabular}

Abbreviations: 1OOA, inferior oblique over action; DVD, dissociated vertical deviation: SOOA, superior oblique over action.

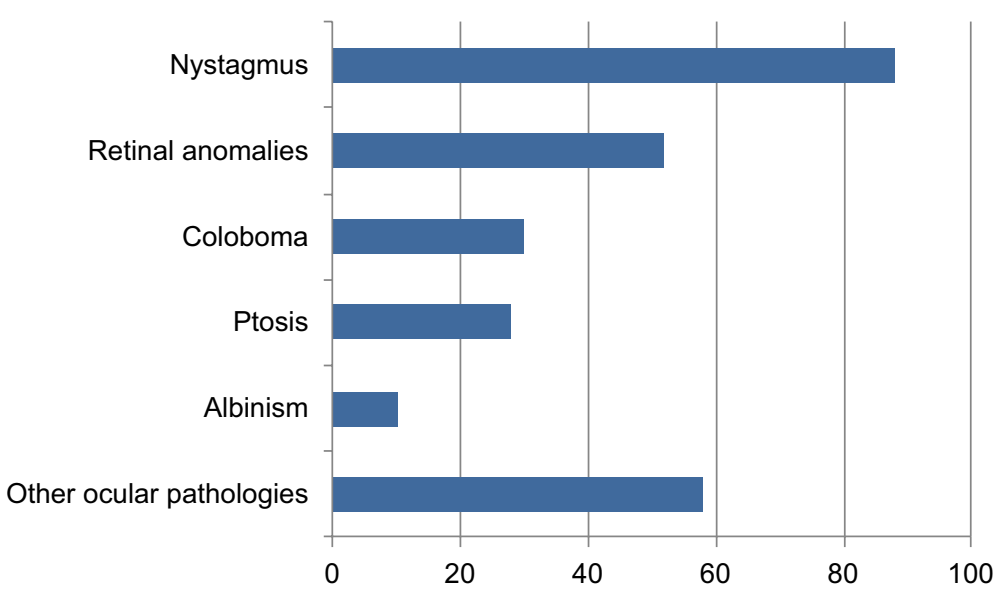

Figure 2 Number of patients with ocular abnormalities and ptosis distribution in strabismic patients. 
found approximately $50 \%$ of all childhood ET were either fully or partially accommodative. ${ }^{18,19}$ Intermittent XT was the most common type of exodeviation. Govindan et $\mathrm{al}^{21}$ also found that intermittent XT was the most common type of exodeviation.

Our results demonstrated that ET and DVD were more prevalent in male patients than female patients and Najafi found a higher prevalence of hypotropia in male patients compared to female patients. ${ }^{22}$

The results of this study along with two studies by Mohney in 2001 and 2007 in Western populations have been matched. In both these studies, the prevalence of accommodative ET was higher than other types of ET. Both our study and that of Mohney et al in 2007 found the highest prevalence of ET in the first decade of life. However, the study of Mohney in 2001 found the prevalence of sensory ET $(6.8 \%)$ to be more than found in this study $(0.6 \%))^{1,3}$

DVD was the second most common association with strabismus, and in our study represented $55.6 \%$ of patients with vertical deviation $(5.9 \%$ of the total number of strabismus patients enrolled in this study); $27.14 \%$ of these patients had the isolated type without any horizontal deviation, whereas the other $72.85 \%$ were associated with horizontal strabismus. However, Helveston ${ }^{23}$ recorded $11.1 \%$ of DVD in 1000 consecutive patients with strabismus and nystagmus, which is about 2-fold of what we encountered in our study.

Helveston $^{23}$ determined the incidence of DVD in both strabismic and nystagmoid patients and found that some of the patients with nystagmus did not have any strabismus. On the other hand, our research found a high prevalence of DVD in nystagmoid patients; therefore, this is the main difference between our study and Helveston's study.

Duane's retraction syndrome (DRS) was also found in 62 patients of which $62 \%$ of them were female and $38 \%$ male. Other studies also found that DRS is more common in females. ${ }^{24,25}$ Our results showed most of the DRS patients had ET but Bhate et $\mathrm{al}^{26}$ found high prevalence of XT in patients with DRS. One of the reasons for this difference is the role of race in the prevalence of strabismus types.

This study found that the majority of strabismic patients (55\%) have amblyopia. Another studies in Iran and Australia have reported strabismus in $23 \%$ and $37 \%$ of amblyopic patients, respectively. ${ }^{20,27}$ Some of the main reasons that this study found the prevalence of amblyopia in strabismic patients was more than Rajavi et $\mathrm{a}^{20}$ found in Iran, and Robaei et $\mathrm{al}^{27}$ found in Australia might be attributed to several factors including: patients not participating in screening programs, an unwillingness to use glasses due to cosmetic problems and that most of the referral patients were financially weak.

In conclusion, accommodative ET is the most common type of strabismus and must be differentiated from other pediatric ET. The results of this study may be used for planning an appropriate eye care program for high risk groups in order to reduce the burden of strabismus and strabismic amblyopia.

\section{Disclosure}

The authors report no conflicts of interest in this work. The authors alone are responsible for the content and writing of the paper.

\section{References}

1. Mohney BG. Common forms of childhood esotropia. Ophthalmology. 2001;108(4):805-809.

2. Pai A, Mitchell P. Prevalence of amblyopia and strabismus. Ophthalmology. 2010;117(10):2043-2044.

3. Greenberg AE, Mohney BG, Diehl NN, Burke JP. Incidence and types of childhood esotropia: a population-based study. Ophthalmology. 2007;114(1):170-174.

4. Friedman Z, Neumann E, Hyams SW, Peleg B. Ophthalmic screening of 38,000 children, age 1 to $2 \frac{1}{2}$ years, in child welfare clinics. J Pediatr Ophthalmol Strabismus. 1980;17(4):261-267.

5. Baiyeroju-Agbeja AM, Owoeye JF. Strabismus in children in Ibadan. Nig J Ophthalmol. 1998;6:31-33.

6. Donnelly UM, Stewart NM, Hollinger M. Prevalence and outcomes of childhood visual disorders. Ophthalmic Epidemiol. 2005;12(4):243-250.

7. Giorgis AT, Bejiga A. Prevalence of strabismus among pre-school children community in Butajira Town. Ethiop J Health Develop. 2017;15(2).

8. Matsuo T, Matsuo C. The prevalence of strabismus and amblyopia in Japanese elementary school children. Ophthalmic Epidemiol. 2005;12(1): 31-36.

9. Friedman DS, Repka MX, Katz J, et al. Prevalence of amblyopia and strabismus in white and African American children aged 6 through 71 months: the Baltimore Pediatric Eye Disease Study. Ophthalmology. 2009;116(11):2128-2134.

10. Amblyopia Preferred Practice Pattern (PPP) guidelines - September 2012. American Academy of Ophthalmology 2014. Available from: https://www.aao.org/preferred-practice-pattern/pediatric-eye-evaluations-ppp-2017. Accessed July 14, 2017.

11. Matsuo T, Matsuo C. Comparison of prevalence rates of strabismus and amblyopia in Japanese elementary school children between the years 2003 and 2005. Acta Medica Okayama. 2007;61(6):329-334.

12. Yu CB, Fan DS, Wong VW, Wong CY, Lam DS. Changing patterns of strabismus: a decade of experience in Hong Kong. Br J Ophthalmol. 2002;86(8):854-856.

13. Medghalchi A. A study on prevalence of horizontal strabismus in patients under 14 years. J Guilan Univ Med Sci. 2003;12(47):80-85.

14. Rah SH, Jun HS, Kim SH. An epidemiologic survey of strabismus among school-children in Korea. J Korean Ophthalmol Soc. 1997; 38(12):2195-2199.

15. Schaal LF, Schellini SA, Pesci LT, Galindo A, Padovani CR, Corrente JE. The prevalence of strabismus and associated risk factors in a southeastern region of Brazil. See comment in PubMed Commons below Semin Ophthalmol_.2016;14:1-4.

16. Bruce A, Santorelli G. Prevalence and risk factors of strabismus in a UK multi-ethnic birth cohort. Strabismus. 2016;24(4):153-160.

17. Ing MR. The Racial Distribution of Strabismus. New York, Strabismus. In: Proceedings of the 3rd Meeting of the International strabismological Association. Grune and Stratton. 1978:107-110. 
18. Nordlow W. Squint - the frequency of onset at different ages, and the incidence of some associated defects in a Swedish population. Acta Ophthalmol. 1964;42(5-6):1015-1037.

19. Roberts J, Rowland M. Refractive status and motility defects of persons 4-74 years, United States 1971-1972. Atlanta: CDC;1978.

20. Rajavi Z, Sabbaghi H, Baghini AS, et al. Prevalence of amblyopia and refractive errors among primary school children. JOphthalmic Vis Res. 2015; 10:408-416.

21. Govindan M, Mohney GB, Diehl NN, Burke JP. Incidence and types of childhood exotropia: a population-based study. Ophthalmology. 2005;112:104-108.

22. Najafi A. Prevalence and management outcome of strabismus in patients of eye surgery center of Shahid Labbafinejad Hospital. Med J Azad Univ. 2007;17(1):33-36.
23. Helveston EM. Dissociated vertical deviation - a clinical and laboratory study. Trans Am Ophthalmol Soc. 1980;78:734-779.

24. Elliot AJ. Duane's Retraction Syndrome. Proc R Soc Med. 1945;38(8): 463-465.

25. Murillo-Correa CE, Kon-Jara V, Engle EC, Zenteno JC. Clinical features associated with an I126M $\alpha 2$-chimaerin mutation in a family with autosomal-dominant Duane retraction syndrome. J Am Assoc Pediat Ophthalmol Strabismus. 2009;13(3):245-248.

26. Bhate M, Sachdeva V, Kekunnaya R. A high prevalence of exotropia in patients with Duane retraction syndrome in a tertiary eye care center in south India. J Pediatr Ophthalmol Strabismus. 2017;54(2):117-122.

27. Robaei D, Rose K, Ojaimi E, Kifley A, Huynh S, Mitchell P. Visual acuity and the causes of visual loss in a population-based sample of 6-yearold Australian children. Ophthalmology. 2005;112(7):1275-1282.
Clinical Optometry

\section{Publish your work in this journal}

Clinical Optometry is an international, peer-reviewed, open access journa publishing original research, basic science, clinical and epidemiologica studies, reviews and evaluations on clinical optometry. All aspects of patient care are addressed within the journal as well as the practice of optometry including economic and business analyses. Basic and clinical

Submit your manuscript here: https://www.dovepress.com/clinical-optometry-journal
Dovepress

research papers are published that cover all aspects of optics, refraction and its application to the theory and practice of optometry. The manuscrip management system is completely online and includes a very quick and fair peer-review system, which is all easy to use. Visit http://www.dovepress. com/testimonials.php to read real quotes from published authors. 